Research Article

\title{
Compact Vitis vinifera-Inspired Ultrawideband Antenna for High-Speed Communications
}

\author{
Jeremiah O. Abolade $\mathbb{C}^{1}{ }^{1}$ Dominic B. O. Konditi, ${ }^{2}$ and Vasant M. Dharmadhikary ${ }^{3}$ \\ ${ }^{1}$ Department of Electrical Engineering, Pan African University, Institute for Basic Sciences, Technology and Innovation, \\ Nairobi, Kenya \\ ${ }^{2}$ School of Electrical and Electronic Engineering, The Technical University of Kenya, Nairobi, Kenya \\ ${ }^{3}$ Department of Electrical and Electronic Engineering, Dedan Kimathi University of Technology, Nyeri, Kenya
}

Correspondence should be addressed to Jeremiah O. Abolade; aboladejeremiah@yahoo.com

Received 28 March 2021; Revised 3 May 2021; Accepted 8 May 2021; Published 18 May 2021

Academic Editor: Giovanni Andrea Casula

Copyright (c) 2021 Jeremiah O. Abolade et al. This is an open access article distributed under the Creative Commons Attribution License, which permits unrestricted use, distribution, and reproduction in any medium, provided the original work is properly cited.

\begin{abstract}
A new compact ultrawideband (UWB) bioinspired antenna is presented in this work. The proposed antenna consists of a vine leaf (Vitis vinifera) shape as the radiating patch, defected ground structure (DGS), and a vertical rectangular slot (VRS) on the ground plane. The vine leaf shape is realized from a circular patch (initiator) in this work. The proposed antenna is built on an FR4 substrate with a dielectric constant of 4.4 , a loss tangent of 0.02 , and a thickness of $1.5 \mathrm{~mm}$. The total dimension of the proposed bioinspired antenna is $35 \times 27.6 \mathrm{~mm}^{2}$. The proposed antenna has a fractional bandwidth of $115.43 \%(3.7 \mathrm{GHz}-13.8 \mathrm{GHz})$ at $10 \mathrm{~dB}$ return loss, a radiation efficiency between $78 \%$ and $97 \%$, a peak gain of $6.7 \mathrm{~dB}$, and a stable radiation pattern. The contributions of this work to the existing literature are as follows: (i) the investigation of a vine leaf shape for UWB antenna application; (ii) the adaptation of the conventional monopole patch antenna design equation to determine the lower edge frequency (LEF) of an arbitrary shape monopole antenna; (iii) the presentation of a compact UWB antenna with high fractional bandwidth compared with recent works in the literature, and (iv) the use of FR4 substrate to achieve a peak radiation efficiency of $97 \%$ with a compact structure.
\end{abstract}

\section{Introduction}

Ultrawideband antenna has attracted the attention of microwave engineers since the declaration of the Federal Communication Commission (FCC) to make it available for commercial use. This antenna readily finds application in radar, military, medical, and mobile communication. According to the FCC, the band designation for UWB is $3.1 \mathrm{GHz}-10.6 \mathrm{GHz}[1]$. Even though this band interferes with other existing standards such as Wi-Fi, WLAN, WiMAX, and the upper ISM band, its advantages such as low power, reasonably cheaper cost of equipment, and its greater noise immunity have made it to become popular in wireless communication systems, especially in short distance communication $[2,3]$.
Over the years, researchers have been working on how to realize a compact antenna having an ultrawide bandwidth. The printed monopole antenna is one of the major techniques being used to achieve such a wide fractional bandwidth. Some of the patch shapes commonly used in the literature are rectangular, triangular, and circular. In recent times, antenna researchers begun to look in the direction of bioinspired structure such as leave shape [4-8], the physical shape of animals [9], or internal organ shape of the animals [10] which has been explored. Authors in [4, 7] proposed a bioinspired UWB antenna based on Igna Marginata leaf. The antenna proposed in [7] has dimension of $40 \times 30 \mathrm{~mm}^{2}$ and is built on an FR4 substrate of height $1.5 \mathrm{~mm}$. A simulated impedance bandwidth of $9.9 \mathrm{GHz}$ was achieved, but the author did not report the radiation efficiency of the antenna. 
The authors in [2] explored maple leaf shape to design the UWB antenna. The antenna was built on Rogers RT 5880 substrate with a relative dielectric constant of 2.2, a loss tangent of 0.0009 , and a height of $1.575 \mathrm{~mm}$. The overall antenna dimension is $30.5 \times 35.5 \mathrm{~mm}^{2}$ and achieves an impedance bandwidth of $3.1 \mathrm{GHz}$ to $13.15 \mathrm{GHz}$ with a $5 \mathrm{GHz}-6 \mathrm{GHz}$ band notch. The authors also did not report the radiation efficiency. Authors in [6] presented a bioinspired antenna based on sugarcane leaf, operating at $700 \mathrm{MHz}$, and a reflector was used to enhance the gain of the proposed antenna. In [11], the authors investigated Tulip flower shape having a dimension $56.25 \times 35.7 \mathrm{~mm}^{2}$ for UWB application, and impedance bandwidth of $9.45 \mathrm{GHz}$ was achieved. Jasmine flower, Ginkgo Biloba, Carica Papaya, and Bidens Pilosa leaves have been designed, fabricated, and analyzed for UWB applications.

The radiation efficiency of an antenna is a critical antenna performance metric in mobile applications where omnidirectional radiation is essential. This is because, radiation efficiency, unlike gain, is a measure of antenna performance without considering the direction of radiation. Notwithstanding, none of the bioinspired UWB antennas in the open literature gives much attention to the radiation efficiency of the reported antennas.

Therefore, in the quest for increased UWB bandwidth and enhanced efficiency, this work investigates vine leaf (Vitis vinifera) shape as a bioinspired structure for UWB wireless applications. The motivation behind this investigation is the sawtooth edge of the vine leaf. In the next section, the vine leaf shape antenna design procedure is presented and then the shape was used as the radiating patch. Section 3 presents the parametric study of the proposed antenna; the measurement results are presented in Section 4; the comparative analysis of the proposed antenna with the relevant existing work in the open literature is presented in Section 5, and the conclusion is presented in Section 6.

\section{Antenna Design Procedure}

The radiating patch of the proposed antenna is based on vine leaf shape on an epoxy glass (FR4) substrate of a dielectric constant of 4.4 , a loss tangent of 0.02 , and a height of $1.5 \mathrm{~mm}$ with a defected ground structure (DGS) and a vertical rectangular (VR) slot as the ground plane. The proposed antenna is fed with a $50 \Omega$ feedline. The proposed antenna dimension is $35 \times 27.6 \mathrm{~mm}^{2}$. Figure 1 shows the picture of a typical vine leaf. The proposed antenna shall hereafter be referred to as vine bioinspired UWB antenna (VBi-UWBA).

The initiator of the VBi-UWBA structure is a circular shape. A circular patch of radius $(r) 10 \mathrm{~mm}$ is chosen as the initiator as shown in Figure 2(a) to achieve a lower edge frequency (LEF) around $3 \mathrm{GHz}$ using equation (1) which is adapted from reference [12]. As shown in Figure 1 , the vine leaf has saw-like edges and the circular shape edge is perturbed to achieve a saw-like edge as shown in Figure 2(b). Hence, the maximum edge length of the $\mathrm{VBi}-\mathrm{UWBA}$ radiating patch from its center is $10 \mathrm{~mm}$

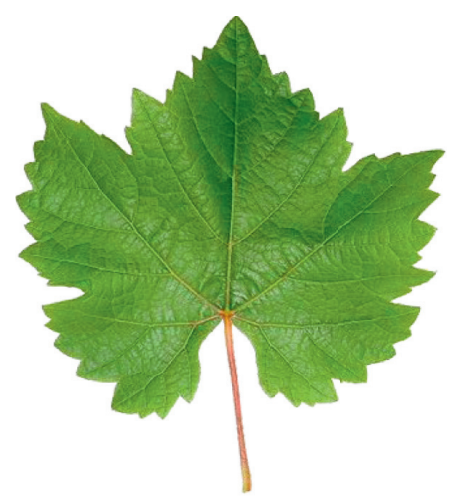

Figure 1: A typical vine leaf shape.

as demonstrated in Figure 2(b). Using the area of a circle given in equation (2), the area of the initiator is $314.2 \mathrm{~mm}^{2}$ but the area of the resultant vine leaf shape is measured to be $221.32 \mathrm{~mm}^{2}$ using the measurement tool of the HFSS simulator. This implies that the resultant radius is $8.39 \mathrm{~mm}$. A $16.1 \%$ reduction is achieved compared with the initiator (CMPA). Using the resultant radius to determine the LEF of the vine leaf shape from equation (1), a LEF of $3.22 \mathrm{GHz}$ is expected compared with $3 \mathrm{GHz}$ of the CMPA. Meanwhile, the lower antenna resonant frequency has also been related to its radiating patch perimeter using equations (3) and (4) in reference [5].

$$
\begin{aligned}
f_{l} & =\frac{0.24 \times 300}{(D+g+(D / 2 \pi)) \times k}(\mathrm{GHz}), \\
\text { area of a circle }(A) & =\pi r^{2}, \\
f_{r}(\mathrm{GHz}) & =\frac{300}{\varphi \sqrt{\varepsilon_{e f f}}}, \\
\varepsilon_{\mathrm{eff}} & \approx \frac{\varepsilon_{r}+1}{2},
\end{aligned}
$$

where $\mathrm{D}$ is the diameter of the circle in millimeter, $g$ is the gap between the edge of the radiating patch and the ground plane in millimeter, $\varepsilon_{r}$ is the dielectric constant of the substrate, $\varphi$ is the perimeter of the patch, $f_{r}$ is the resonant frequency, and $k$ accounts for the effect of dielectric permittivity of the substrate, and it is taken to be 1.15 [12].

The proposed VBi-UWBA geometry is presented in Figure 3. Table 1 presents the XY-points coordinates of the proposed Vitis vinifera leaf radiating patch which are extracted from the graphing technique for repeatability purposes.

The design parameters labeled in Figure 4 are as presented in Table 2.

\section{Parametric Study and Analysis of VBi-UWBA}

In this section, the parametric analysis of VBi-UWBA is presented. This is done to evaluate the effect of the design parameters on the resonant frequency. 


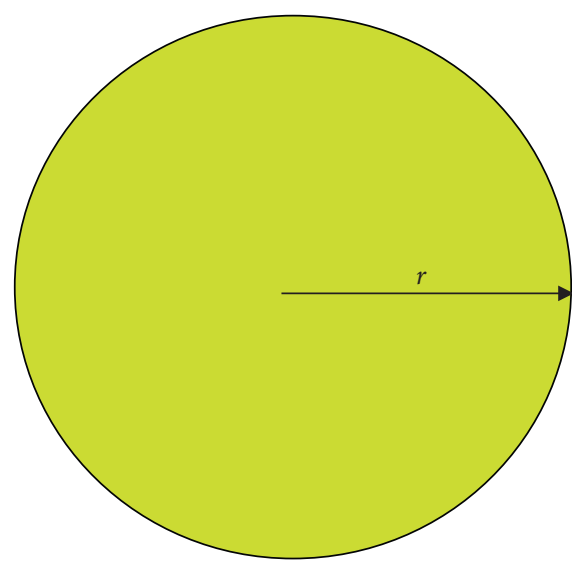

(a)

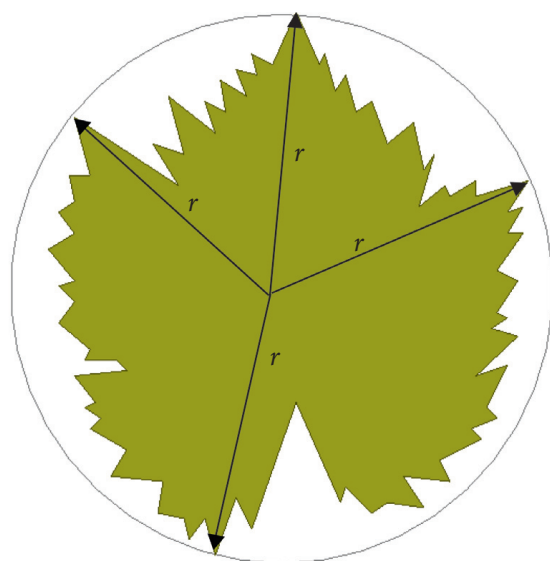

(b)

FIGURE 2: Vine leaf shape realization procedure: (a) the initiator circular patch; (b) the realized vine leaf shape.
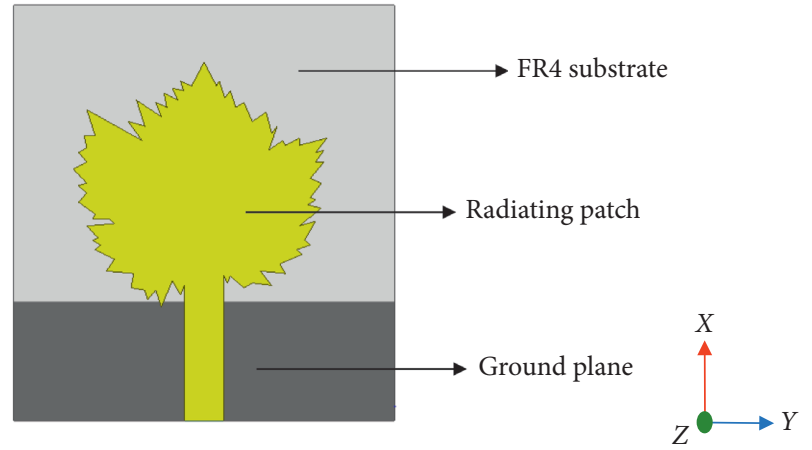

Figure 3: Proposed compact bioinspired UWB antenna.

3.1. The Effect of the Length of the Defected Ground $\left(\mathbf{L}_{\mathbf{g}}\right)$. To evaluate the effect of $L_{g}$, the slot was eliminated and $L_{g}$ varies from $20 \mathrm{~mm}$ to $5 \mathrm{~mm}$ with an interval of $3 \mathrm{~mm}$. The response is as shown in Figure 5. It can be observed that the length of the ground plane has a tremendous effect on the performance of the proposed structure. It can be seen that a UWB with a $-10 \mathrm{~dB}$ fractional bandwidth of $118.1 \%$ $(3.21 \mathrm{GHz}-12.47 \mathrm{GHz})$ can be achieved only when $L_{g}$ $=10 \mathrm{~mm}$. When $L_{g}=11 \mathrm{~mm}$, the reflection coefficient response demonstrates a UWB with a bandgap between $8.41 \mathrm{GHz}$ and $9.46 \mathrm{GHz}$. For $L_{g}=5 \mathrm{~mm}$, the first resonance mode is at $2.87 \mathrm{GHz}$ which is the lowest resonant mode of all the $L_{g}$ variation.

It can be observed that as $L_{g}$ increases, the fundamental resonance frequency increases. This effect can be traced to the change in the antenna impedance matching with the $50 \Omega$ feedline because as the capacitive reactance formed by the dielectric-filled gap between the radiating patch and the ground varies with the variation in the length of the ground plane, there is a corresponding variation in the overall antenna impedance which can cause impedance mismatch.
TABLE 1: The point coordinates of the proposed Vitis vinifera leafshaped radiating patch.

\begin{tabular}{ccccccccc}
\hline \multicolumn{7}{c}{ Semi-vine leaf coordinate points } \\
$N$ & $X$ & $y$ & $N$ & $x$ & $y$ & $N$ & $X$ & $y$ \\
\hline 1 & -10.0 & 0.0 & 35 & 7.8 & 5.9 & 69 & -2.8 & -8.0 \\
2 & -8.0 & 0.9 & 36 & 7.6 & 4.1 & 70 & -3.8 & -8.2 \\
3 & -8.4 & 1.1 & 37 & 8.8 & 4.9 & 71 & -3.8 & -7.4 \\
4 & -7.0 & 1.5 & 38 & 8.6 & 3.5 & 72 & -6.0 & -8.0 \\
5 & -7.6 & 1.9 & 39 & 9.0 & 2.9 & 73 & -3.4 & -4.2 \\
6 & -6.2 & 2.3 & 40 & 8.0 & 1.9 & 74 & -5.0 & -5.2 \\
7 & -6.6 & 2.9 & 41 & 8.6 & 1.7 & 75 & -4.6 & -4.0 \\
8 & -5.0 & 3.5 & 42 & 4.8 & 0.0 & 76 & -6.8 & -4.6 \\
9 & -5.8 & 4.5 & 43 & 9.6 & -1.6 & 77 & -5.4 & -2.9 \\
10 & -4.0 & 4.9 & 44 & 8.4 & -2.2 & 78 & -6.6 & -3.3 \\
11 & -4.6 & 5.3 & 45 & 10.6 & -2.9 & 79 & -6.2 & -2.5 \\
12 & -2.6 & 4.7 & 46 & 9.2 & -3.3 & 80 & -7.4 & -2.7 \\
13 & -3.4 & 5.7 & 47 & 10.0 & -3.9 & 81 & -6.8 & -1.8 \\
14 & -3.0 & 5.9 & 48 & 9.2 & -4.0 & 82 & -7.8 & -2.2 \\
15 & -3.6 & 6.9 & 49 & 9.0 & -5.0 & 83 & -7.6 & -1.4 \\
16 & -3.0 & 6.9 & 50 & 7.8 & -4.8 & 84 & -8.4 & -1.6 \\
17 & -3.6 & 8.9 & 51 & 7.6 & -6.7 & 85 & -8.0 & -0.8 \\
18 & -2.4 & 8.1 & 52 & 6.6 & -6.1 & & & \\
19 & -2.6 & 8.7 & 53 & 5.8 & -7.4 & & & \\
20 & -1.6 & 8.1 & 54 & 5.4 & -7.0 & & & \\
21 & -1.6 & 8.7 & 55 & 5.0 & -7.6 & & & \\
22 & -0.2 & 7.7 & 56 & 4.8 & -7.2 & & & \\
23 & 0.2 & 8.5 & 57 & 3.8 & -8.0 & & & \\
24 & 1.4 & 7.7 & 58 & 3.6 & -6.1 & & & \\
25 & 1.6 & 8.1 & 59 & 3.2 & -6.5 & & & \\
26 & 2.0 & 7.5 & 60 & 3.2 & -7.6 & & & \\
27 & 2.3 & 8.5 & 61 & 2.8 & -7.4 & & & \\
28 & 3.8 & 6.9 & 62 & 1.8 & -8.6 & & & \\
29 & 3.4 & 8.1 & 63 & 1.0 & -8.0 & & & \\
30 & 5.0 & 7.3 & 64 & 0.4 & -8.6 & & & \\
31 & 5.4 & 7.7 & 65 & 0.2 & -8.0 & & & \\
32 & 5.8 & 6.7 & 66 & -1.0 & -8.9 & & & \\
33 & 6.2 & 7.1 & 67 & -1.6 & -8.0 & & & \\
34 & 7.0 & 5.5 & 68 & -2.4 & -8.6 & & & \\
\hline & & & & & & & &
\end{tabular}




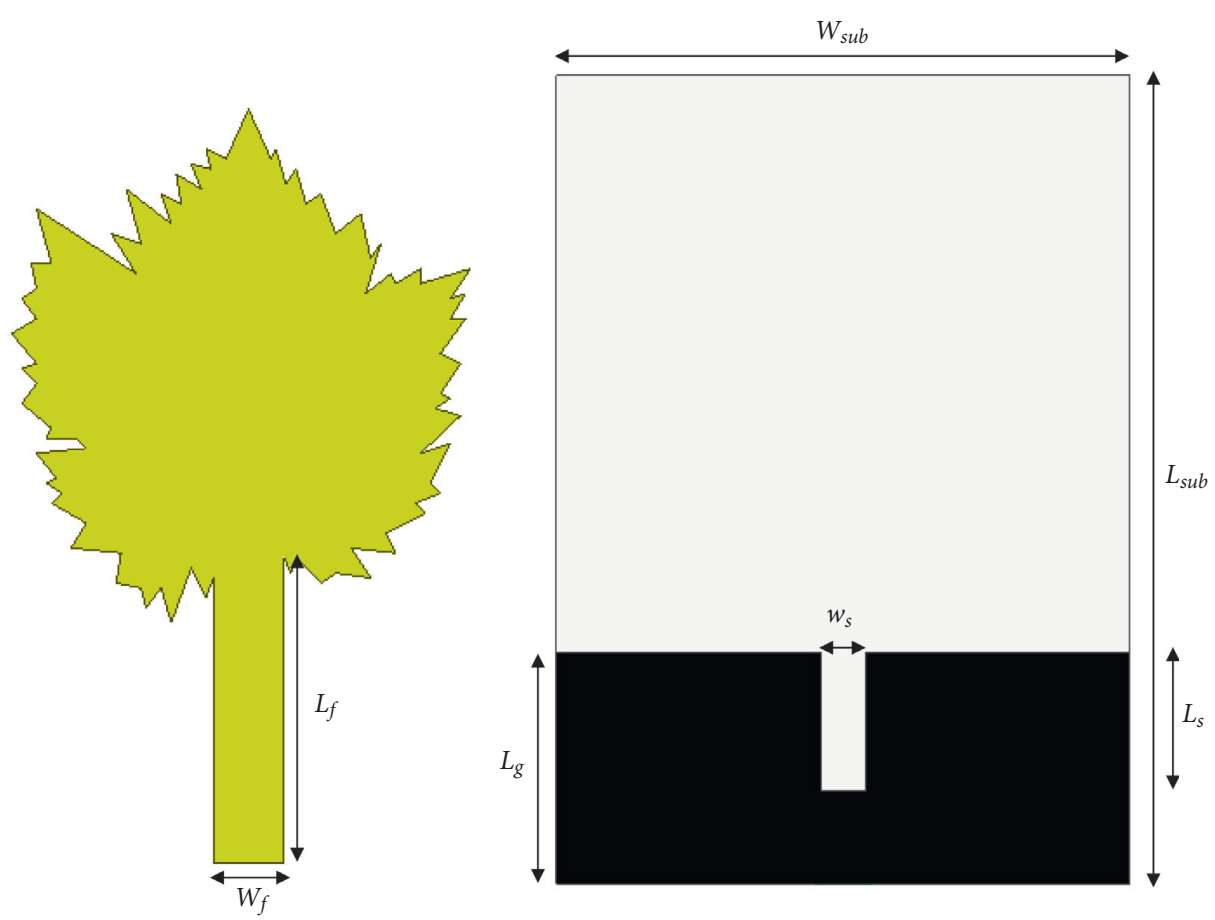

FIgURE 4: The VBi-UWBA separating the radiating patch from the substrate and ground plane.

TABLE 2: VBi-UWBA optimal design parameters.

\begin{tabular}{cccc}
\hline S/N & Parameter & Description & $\begin{array}{c}\text { Value } \\
(\mathrm{mm})\end{array}$ \\
\hline 1 & $W_{\text {sub }}$ & Width of the substrate & 27.6 \\
2 & $L_{\text {sub }}$ & $\begin{array}{c}\text { Length of the substrate } \\
\text { Length of the slot on the ground }\end{array}$ & 35.0 \\
3 & $L_{s}$ & Width of the slot on the ground & 2.182 \\
4 & $w_{s}$ & Length of the ground plane & 10.0 \\
5 & $L_{g}$ & Width of the feedline & 2.8 \\
6 & $W_{f}$ & Length of the feedline & 12.3 \\
7 & $L_{f}$ & Radius of the initiator & 10.0 \\
8 & $r$ & Separation between patch and ground & 0.00 \\
9 & $g$ &
\end{tabular}

It can also be observed that as $L_{g}$ increases from $5 \mathrm{~mm}$ to $14 \mathrm{~mm}$, the LEF is simultaneously increasing. Notwithstanding, LEF starts decreasing again from $L_{g}=17 \mathrm{~mm}$ and above. Therefore, $L_{g}$ can be used for tuning the LEF of a monopole antenna. Because the focus of this work is UWB, the optimized $L_{g}$ is therefore taken to be $10 \mathrm{~mm}$ based on this parametric analysis.

3.2. The Effect of Slot Length $\left(L_{s}\right)$. Figure 6 shows the effect of $L_{s}$ on reflection coefficient while keeping $L_{g}$ and $W_{s}$ at $10 \mathrm{~mm}$ and $2.18 \mathrm{~mm}$, respectively. It is observed that the VR slot on the ground plane affects the return loss at the resonance rather than creating another resonance at a new frequency. It is can be seen that at the lower resonance frequency, the best return loss $(31.3 \mathrm{~dB})$ is achieved when $L_{s}=4 \mathrm{~mm}$. Notwithstanding, at this value of $L_{s}$, the return

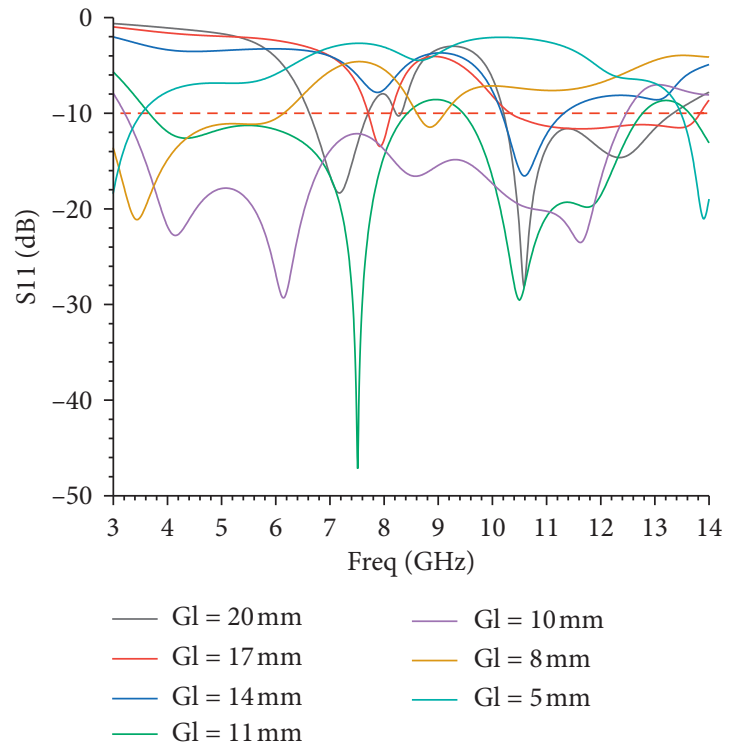

Figure 5: Effect of $L_{g}$ variation on the reflection coefficient.

loss is relatively poor around $9.2 \mathrm{GHz}$ compared with when it is $3 \mathrm{~mm}, 5 \mathrm{~mm}$, and $6 \mathrm{~mm}$.

It can be seen that, though, the return loss response when $L_{s}=6 \mathrm{~mm}$ is saggy from $3.22 \mathrm{GHz}$ to $12.47 \mathrm{GHz}$. Hence, $6 \mathrm{~mm}$ is chosen as the optimized value of $L_{s}$. It is observed that slot in the ground plane enhances the return loss which is a result of matching the antenna impedance to the feedline 


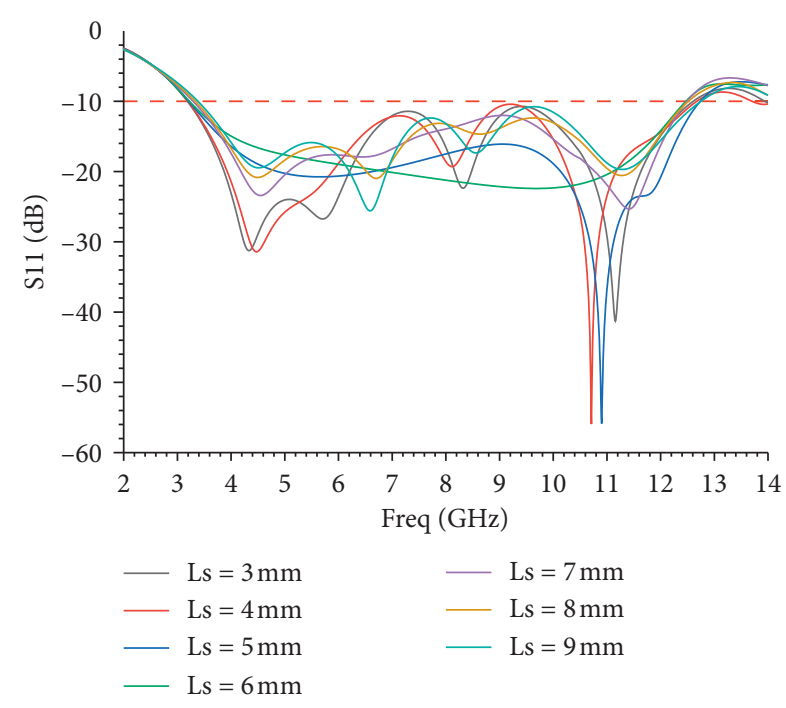

Figure 6: Effect of $L_{s}$ variation on the reflection coefficient.

impedance by reducing the capacitive reactance introduced by the feedline and thereby enhances the impedance matching of the antenna.

3.3. The Effect of Slot Width $\left(W_{s}\right)$. The effect of the slot width of the ground plane is presented in Figure 7. It can be seen that $W_{s}$ has almost the same effect as the slot length. It is observed that UWB is achievable at $1 \mathrm{~mm}, 1.5 \mathrm{~mm}, 2 \mathrm{~mm}$, and $2.182 \mathrm{~mm}$ values of $W_{s}$ without a notch between $3.1 \mathrm{GHz}-12.38 \mathrm{GHz}$, respectively. Meanwhile, $2.5 \mathrm{~mm}$ and $3.25 \mathrm{~mm}$ values of $W_{s}$ demonstrate a band notch within the UWB between $8.55 \mathrm{GHz}$ and $9.60 \mathrm{GHz} .2 .182 \mathrm{~mm}$ gives a better return loss response. Hence, the optimized parameter of $W_{s}$ is taken to be $2.182 \mathrm{~mm}$. It is noted that $W_{s}$ does not have a considerable effect on the LEF of the proposed structure but there is a notable effect on the return loss. Hence, the width of the slot can be used to enhance the return loss of VBi-UWBA.

Therefore, the optimized value of the defected ground plane is given in Table 2.

\section{Results and Discussion}

The prototype of the proposed antenna is as shown in Figure 8. Figure 8(a) shows the top layer (the vine radiating patch and the feedline), and the ground plane is shown in Figure 8(b). The reflection coefficient measurement setup is as shown in Figure 9. The Rhode and Schwaz ZVA50 Vector Network Analyzer is used for the reflection coefficient measurement of the proposed VBi-UWBA.

4.1. Simulated and Measured Reflection Coefficient. Figure 10 shows the simulated and measured reflection coefficient of the proposed bioinspired UWB antenna. It can be seen from the simulation that the VBi-UWBA has a fractional bandwidth of $117.9 \%(3.26 \mathrm{GHz}-12.62 \mathrm{GHz})$ at a return loss of $10 \mathrm{~dB}$. It can be observed that the LEF of the simulation $(3.26 \mathrm{GHz})$ agrees with the LEF predicted

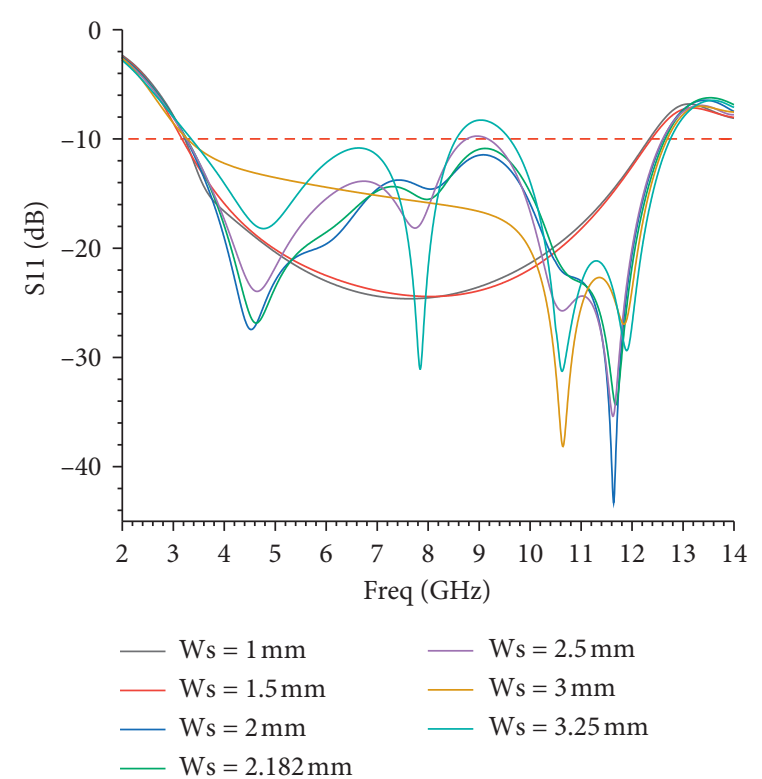

FIgURE 7: Effect of $W_{s}$ variation on the reflection coefficient.

(3.22 GHz) in Section 2. In the case of the measurement, the proposed antenna demonstrated UWB with a fractional bandwidth of $115.43 \%(3.7 \mathrm{GHz}-13.8 \mathrm{GHz})$ at $-10 \mathrm{~dB}$.

The shift in the LEF in the measurement can be traced to the effect of the SMA connector and the soldering. Nonetheless, both simulated and measured impedance bandwidth at $-10 \mathrm{~dB}$ is in good agreement. The measurement result of the proposed VBi-WBA shows that it is well suitable for UWB application as it covers the entire band allocated for UWB and outperforms the existing bioinspired UWB antennas reported in the open literature.

4.2. Radiation Pattern. The radiation pattern of the proposed VBi-UWBA is investigated at $4.5 \mathrm{GHz}, 5.5 \mathrm{GHz}$, $7.5 \mathrm{GHz}, 10.5 \mathrm{GHz}$, and $13.5 \mathrm{GHz}$ which are presented as shown in Figures 11(a)-11(e), respectively. It can be observed that the radiation pattern at $4.5 \mathrm{GHz}$ and $5.5 \mathrm{GHz}$ is bidirectional in $\mathrm{XZ}$-plane while the $\mathrm{XZ}$-plane radiation patterns at $7.5 \mathrm{GHz}, 10.5 \mathrm{GHz}$, and $13.5 \mathrm{GHz}$ are quasiomnidirectional. At YZ-plane, the radiation patterns are omnidirectional in all the investigated frequencies.

At $4.5 \mathrm{GHz}$, the direction of the main lobe is at $176^{\circ}$ and the angular width $(3 \mathrm{~dB})$ is $112^{\circ}$ for $\mathrm{XZ}$-plane as shown in Figure 11(a). As can be seen in Figure 11(b), the $5.5 \mathrm{GHz}$ XZplane radiation pattern has its main lobe direction at $166^{\circ}$ and the $3 \mathrm{~dB}$ angular width is $106^{\circ}$. Furthermore, at $7.5 \mathrm{GHz}$, the main lobe direction is at $16^{\circ}$ and the $3 \mathrm{~dB}$ angular width is $78^{\circ}$ at XZ-plane as shown in Figure 11(c). As shown in Figure $11(\mathrm{~d})$, at $10.5 \mathrm{GHz}$, the main lobe direction is at $30^{\circ}$ and the angular width $(3 \mathrm{~dB})$ is $54^{\circ}$ at XZ-plane. In the case of $13.5 \mathrm{GHz}$, the main lobe direction is at $68^{\circ}$ and its $3 \mathrm{~dB}$ angular width is $56^{\circ}$ as shown in Figure 11(e). Hence, the proposed $\mathrm{VBi}-\mathrm{UWBA}$ has a stable radiation pattern through the entire bandwidth. These characteristics make VBiUWBA a good candidate for mobile applications. 


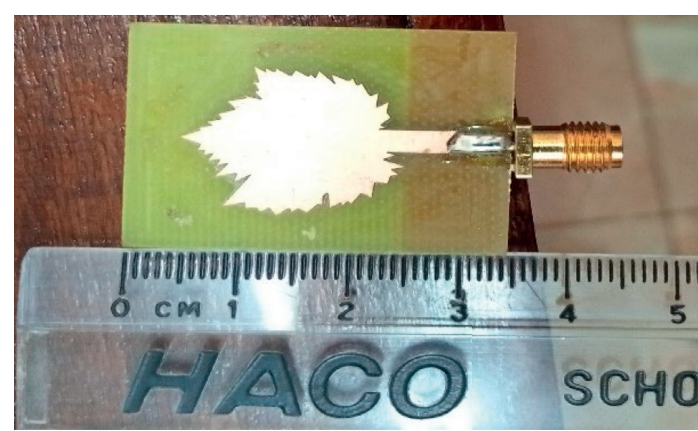

(a)

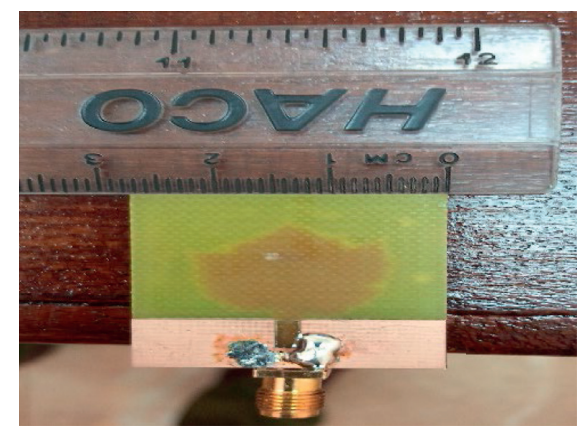

(b)

Figure 8: The prototype of the proposed VBi-UWBA (a) top layer and (b) ground plane.

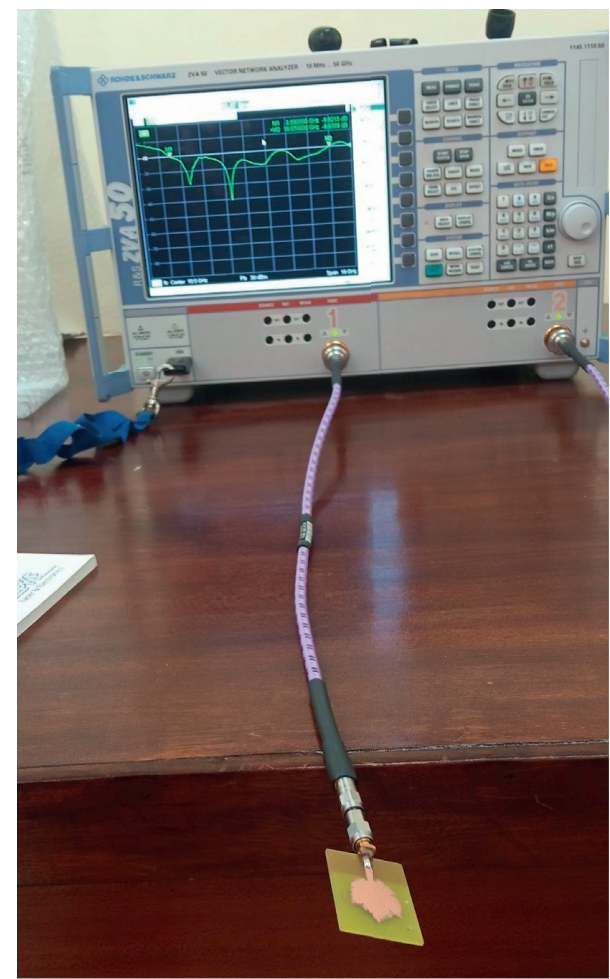

FIGURE 9: The measurement setup for reflection coefficient of the VBi-UWBA.

4.3. The Gain and Radiation Efficiency of the Proposed VBi$U W B A$. Antenna gain shows how well the antenna radiates energy in a particular direction, but radiation efficiency shows how well an antenna utilizes the received power for radiation in all directions. Equations (5) and (6) present the theoretical formula for gain and radiation efficiency, respectively. The gain of VBi-UWBA at $4.5 \mathrm{Ghz}, 5.5 \mathrm{GHz}$, $7.5 \mathrm{GHz}, 10.5 \mathrm{GHz}$, and $13.5 \mathrm{GHz}$ is presented in Figure 12 . A peak gain of $2.9 \mathrm{~dB}, 3.5 \mathrm{~dB}, 4.7 \mathrm{~dB}, 3.4 \mathrm{~dB}$, and $6.7 \mathrm{~dB}$ is achieved at $4.5 \mathrm{Ghz}, 5.5 \mathrm{GHz}, 7.5 \mathrm{GHz}, 10.5 \mathrm{GHz}$, and 13.5 $\mathrm{GHz}$, respectively. This shows that the proposed antenna has a suitable gain across the UWB.
The radiation efficiency and the axial ratio of the proposed VBi-UWBA are presented in Figure 13. It can be observed that the proposed antenna demonstrates high radiation efficiency ranging from $78 \%$ to $97 \%$. As far as we know, this is the highest peak radiation efficiency reported in the literature for compact UWB antenna applications with FR4 substrate. It can be observed in Figure 13 that at $11.5 \mathrm{GHz}$, the proposed VBi-UWBA demonstrates circular polarization with a $2.2 \% 3 \mathrm{~dB}$ axial ratio bandwidth (ARBW).

$$
\begin{aligned}
G(\varphi, \theta) & =4 \pi \frac{U(\varphi, \theta)}{P_{\text {in }}}, \\
e & =\frac{R_{r}}{R_{r}+R_{L}},
\end{aligned}
$$

where $G(\varphi, \theta)$ is the total gain, $e$ is the efficiency, $U(\varphi, \theta)$ is the radiation intensity, $P_{i n}$ is the total input power, $R_{r}$ is the radiation resistance, and $R_{L}$ is the radiation losses.

4.4. The Current Distribution of VBi-UWBA. In order to have a full understanding of the operation of the proposed VBiUWBA, a study of its current distribution is performed and presented in this section. From Section 3.1, it can be observed that there are four excitation modes which occur at $4.6 \mathrm{GHz}, 8 \mathrm{GHz}, 10.8 \mathrm{GHz}$, and $11.5 \mathrm{GHz}$, respectively. Therefore, the investigation of the mode of operation of the proposed VBi-UWBA is done at these frequencies using its surface current distribution. Figure 14 shows the current distribution at the aforesaid frequencies.

The current distribution of the fundamental mode is as shown in Figure 14(a). It can be observed that the current flows toward the top tip of the radiating patch with the higher density current flowing along the edge. In addition, at the ground plane, the current flows toward the edge of the VR slot to near the radiating patch. This excitation mode is equivalent to the fundamental mode (TE11) of a circular patch (initiator). The calculated resonant frequency of this mode is $4.7 \mathrm{GHz}$ using the circular patch antenna design equation given as follows, which agrees with the computation result: 


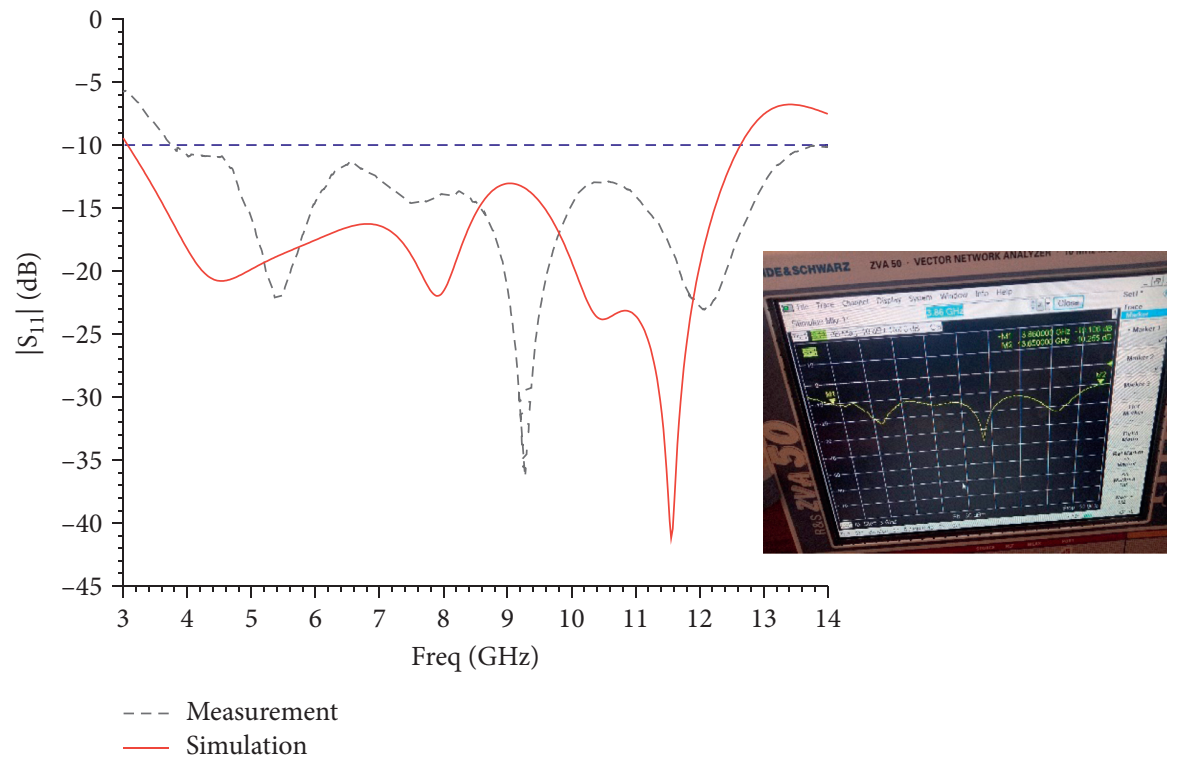

Figure 10: Reflection coefficient of VBi-UWBA.

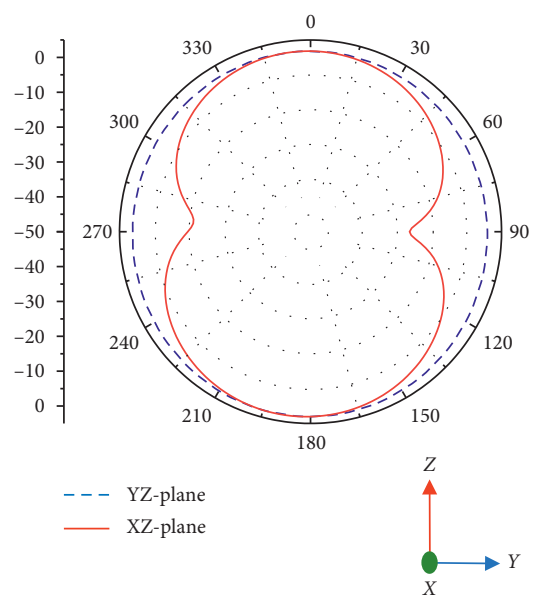

(a)
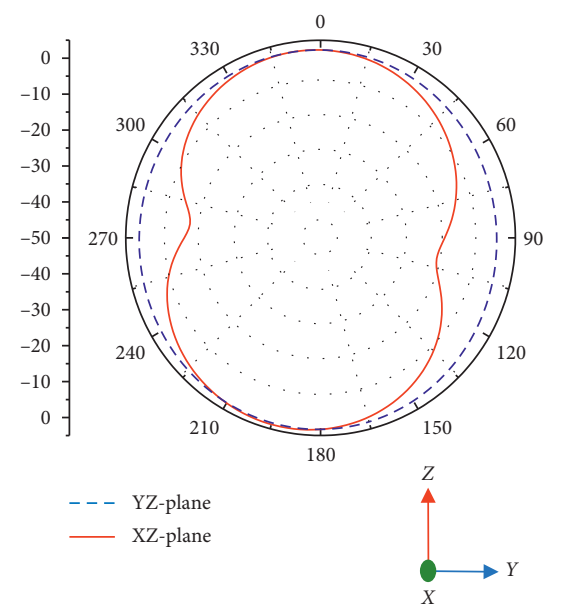

(b)

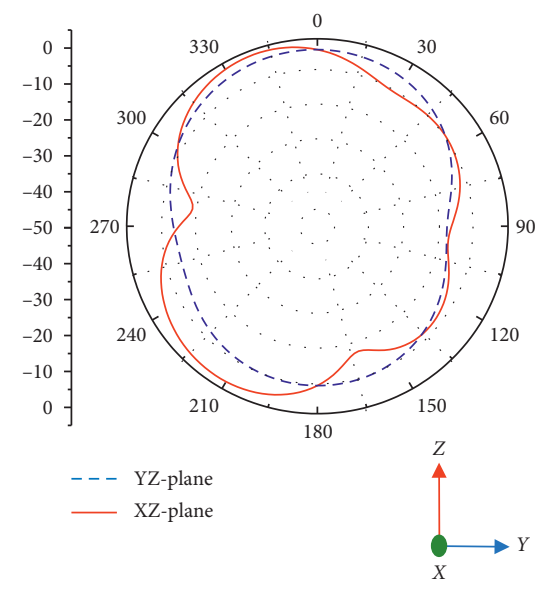

(c)

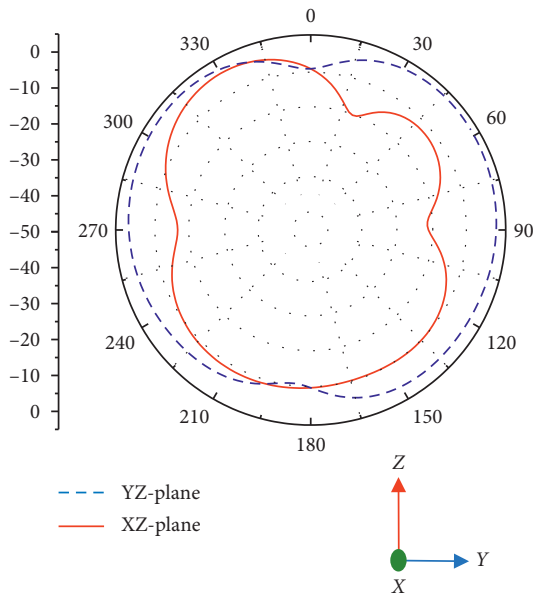

(d)

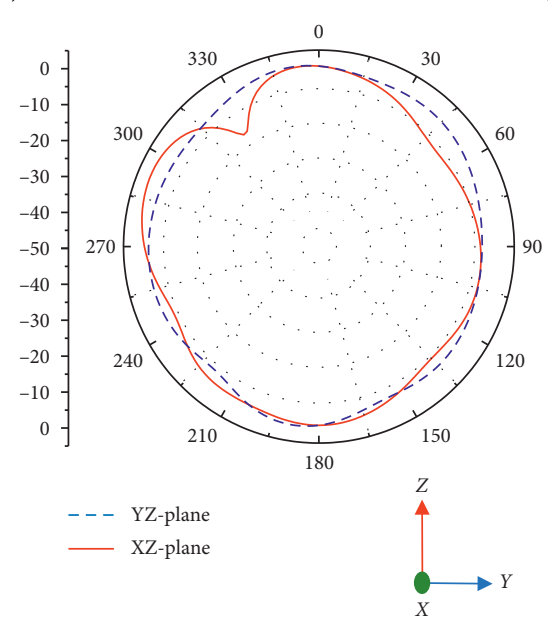

(e)

FIgURE 11: Simulated radiation pattern of proposed VBi-UWBA. 


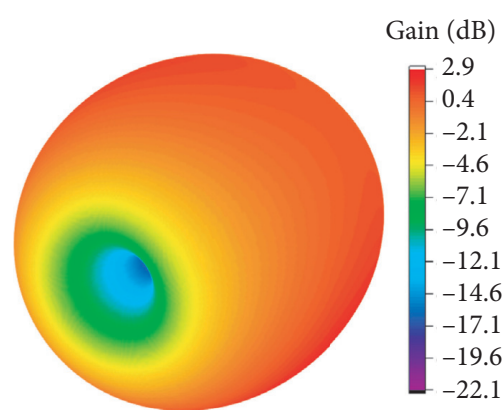

(a)

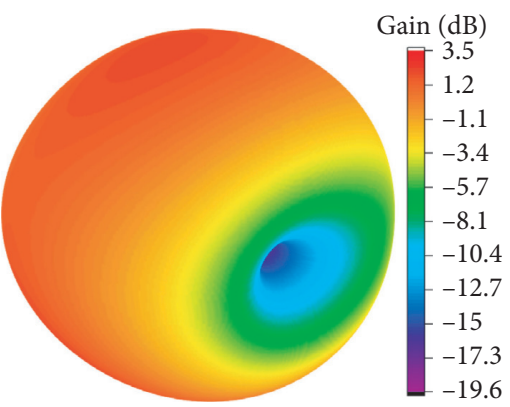

(b)

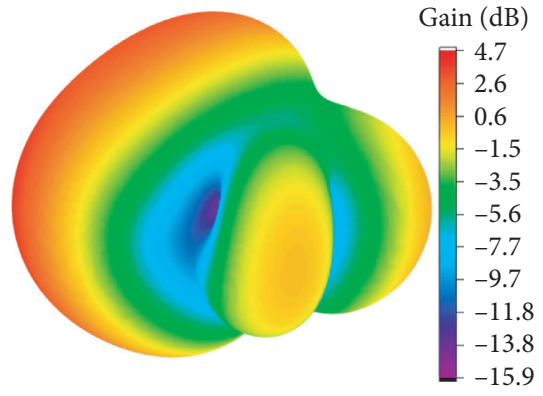

(c)

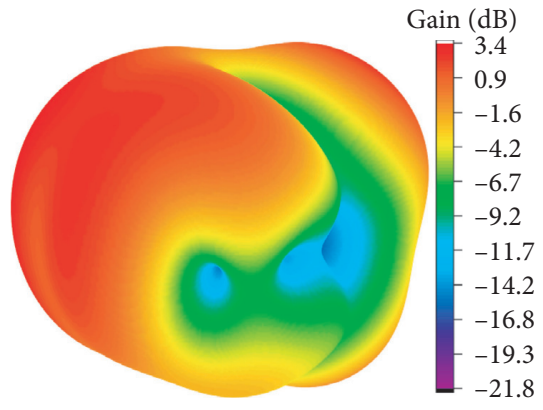

(d)

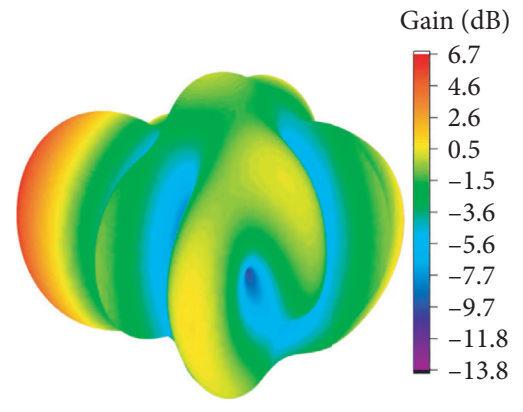

(e)

Figure 12: The simulated 3D gain of the proposed VBi-UWBA at (a) $4.5 \mathrm{GHz}$, (b) $5.5 \mathrm{GHz}$, (c) $7.5 \mathrm{GHz}$, (d) $10.5 \mathrm{GHz}$, and (e) $13.5 \mathrm{GHz}$.

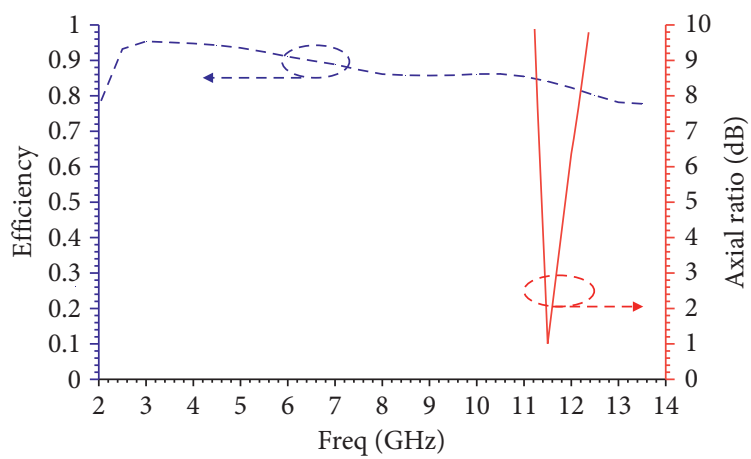

FIGURE 13: The simulated radiation efficiency and the axial ratio of the proposed VBi-UWBA.
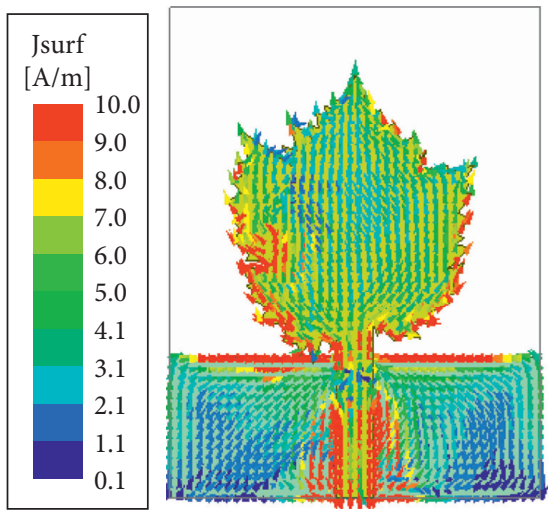

(a)

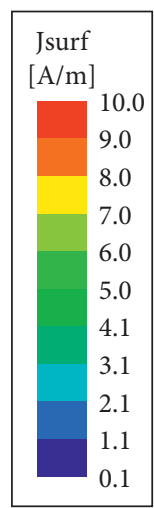

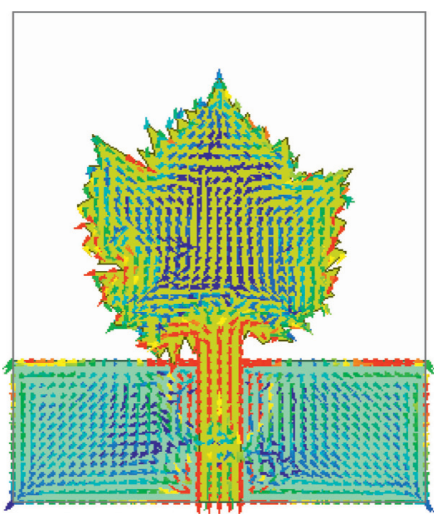

(b)

FIGURE 14: Continued. 

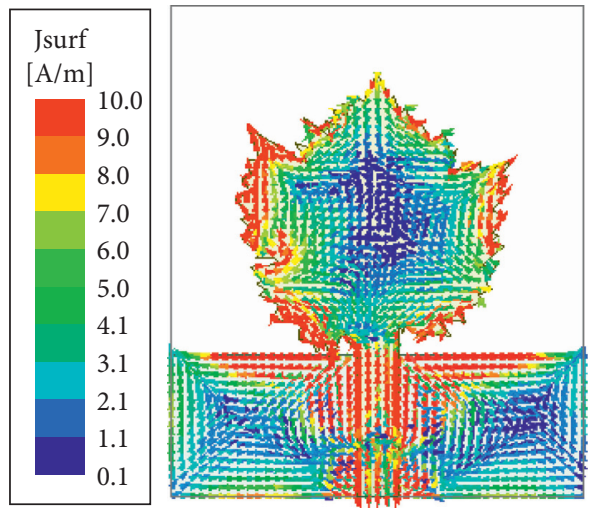

(c)
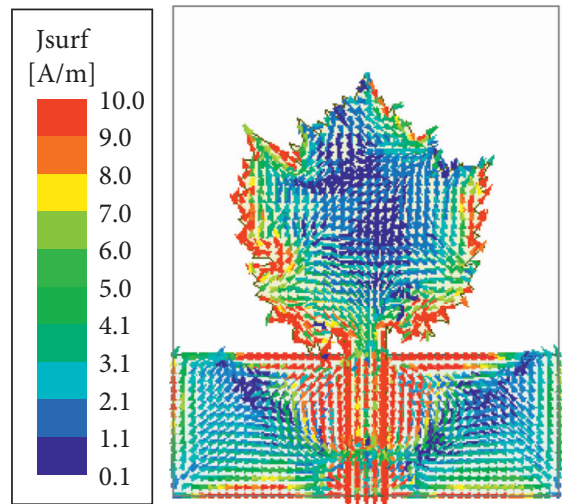

(d)

FIGURE 14: Simulated vector surface current distribution of the proposed VBi-UWBA at (a) $4.6 \mathrm{GHz}$, (b) $8 \mathrm{GHz}$, (c) $10.8 \mathrm{GHz}$, and (d) $11.5 \mathrm{GHz}$.

$$
\begin{aligned}
f_{n m} & =\frac{X_{n m} C}{2 \pi a_{e} \sqrt{\varepsilon_{r}}} \\
a_{e} & =a\left(\sqrt{1+\frac{2 h}{\pi a \varepsilon_{r}}\left(\operatorname{In} \frac{\pi a}{2 h}+1.7726\right)}\right),
\end{aligned}
$$

where $a$ is the radius of the radiating patch which in our case is $8.39 \mathrm{~mm}$ and $X_{n m}$ is the $m$ th zero of the derivative of $J_{n}(k a)$.

Figure 14(b) shows the current distribution at $8 \mathrm{GHz}$; it can be observed that different modes are excited which leads to a null at the center of the radiating patch. This scenario justifies why the resonance at this frequency almost disappeared. At this frequency, the current is seen to be flowing towards the two bottom edges of the ground plane.

The current distribution at $10.8 \mathrm{GHz}$ is as shown in Figure $14(\mathrm{c})$. Just like in the case of $8 \mathrm{GHz}$, many modes are excited by the antenna and therefore a null can be observed at the center of the radiating patch as well as the two halves of the ground plane, hence poor resonance. At $11.5 \mathrm{GHz}$, the current distribution is seen to be rotating in with time. Therefore, circular polarization is achieved at this frequency. The CP achieved at this frequency $(11.5 \mathrm{GHz})$ is due to the excitation of two linear modes with a $90^{\circ}$ phase shift as seen in Figure 14. This could be traced to the asymmetric topology of the Vitis vinifera leaf-shaped and not the feeding technique [13]. With this analysis, it can be clearly stated that excitation of several modes which are added constructively leads to the UWB nature of the proposed VBi-UWBA in this work.

4.5. Group Delay of $V B i-U W B A$. Group delay is another performance metric of the UWB antenna which shows the degree of distortion between the antenna transmitting and the receiving antenna. In order to evaluate the group delay of VBi-UWBA, a face-to-face configuration of two VBiUWBAs is set up at $300 \mathrm{~mm}$ apart for the far-field scenario as shown in Figure 15. It can be seen from Figure 16 that the group delay of VBi-UWBA is around $0.1 \mathrm{~ns}$ from $3 \mathrm{GHz}$ to 12.4 GHz. There is a little spike to $1.2 \mathrm{~ns}$ at $13.2 \mathrm{GHz}$ but

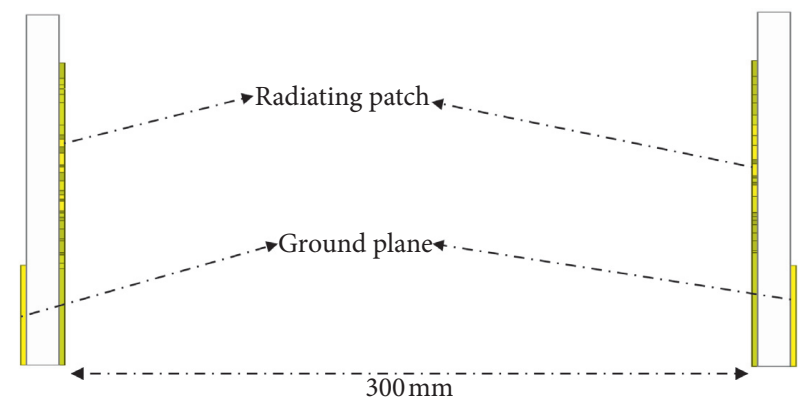

Figure 15: Face-to-face configuration of two VBi-UWBAs.

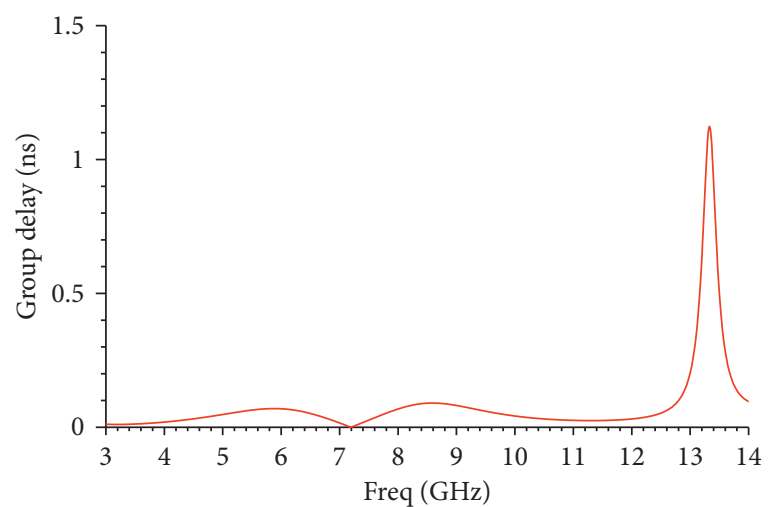

FIGURE 16: Simulated group delay of VBi-UWBA.

which is still within the acceptable limit. Hence, there is a negligible distortion in the signal of the UWB system. With this analysis, the proposed VBi-UWBA is suitable for highspeed UWB communication.

\section{Comparative Analysis of VBi-UWBA with Recent Works in the Literature}

Table 3 presents the comparative analysis of the VBi-UWBA structure with the existing works in the literature. Though the antenna proposed in $[1,4,8,16,22,23]$ is comparatively small 
TABLE 3: Comparative analysis of VBi-UWBA with the existing literature.

\begin{tabular}{|c|c|c|c|c|c|}
\hline Ref & Size $\left(\lambda_{0}^{2}\right)$ & Substrate & $\mathbf{f}_{\mathbf{l}} / \mathbf{f}_{\mathbf{h}}(\mathrm{GHz})$ & Peak gain $(\mathrm{dB})$ & Rad. efficiency (\%) \\
\hline [14] & $0.4 \times 0.4$ & RT Duroid 5880 & $3 / 10.8$ & 4.7 & NR \\
\hline$[15]$ & $0.5 \times 0.4$ & FR4 & $3.1 / 10.6$ & 5.2 & NR \\
\hline [16] & $0.2 \times 0.2$ & FR4 & $1.4 / 11.3$ & 4.6 & NR \\
\hline [17] & $0.4 \times 0.4$ & Arlon Diclad 880A & $1.79 / 28.02$ & 8.0 & NR \\
\hline [1] & $0.4 \times 0.2$ & FR4 & $3 / 10.6$ & NR & NR \\
\hline [8] & $0.4 \times 0.2$ & FR4 & $1.9 / 6.2$ & 10.2 & NR \\
\hline [18] & $0.3 \times 0.2$ & FR4 & $1.8 / 12$ & 4.0 & $78-96$ \\
\hline [19] & $0.4 \times 0.4$ & FR4 & $2.8 / 14$ & 5.0 & $75-90$ \\
\hline [4] & $0.3 \times 0.3$ & FR4 & $0.5 / 1.5$ & 2.81 & NR \\
\hline [7] & $0.4 \times 0.3$ & FR4 & $2.74 / 13$ & $6.2 \mathrm{dBi}$ & NR \\
\hline [20] & $0.1 \times 0.2$ & FR4 & $3.07-11.6$ & 5.5 & $35-90$ \\
\hline [21] & $0.4 \times 0.3$ & FR4 & $2.9 / 15$ & 4.5 & $90^{*}$ \\
\hline [22] & $0.2 \times 0.2$ & FR4 & $3 / 20$ & 4.0 & $70^{*}$ \\
\hline [23] & $0.3 \times 0.3$ & FR4 & $3.05 / 11.9$ & 5.9 & $94^{+}$ \\
\hline$[24]$ & $0.4 \times 0.5$ & FR4 & $3.1 / 10.6$ & 2.5 & NR \\
\hline This work & $0.4 \times 0.3$ & FR4 & $3.7 / 13.8$ & 6.7 & $78-97$ \\
\hline
\end{tabular}

NR: not reported; ${ }^{*}$ indicates average value; ${ }^{+}$indicates total value.

than the proposed antenna in this work, it was observed that the peak gain of the proposed antenna is higher than the peak gain reported by the authors and the radiation efficiency is not reported. The antenna proposed in this work is comparatively compact than the antenna reported in $[15,17,19,24,25]$ as shown in Table 3. Although the proposed antenna in [20] has a compact size nonetheless with a peak group delay and minimum radiation efficiency of $4 \mathrm{~ns}$ and $35 \%$ while in this work, a peak group delay and minimum radiation efficiency are $1.1 \mathrm{~ns}$ and $78 \%$, respectively. It can be observed that the antenna proposed in [21] has a similar size to the antenna proposed in this work but with a lesser peak gain. It can be observed that VBi-UWBA outperformed the reported bioinspired UWB antennas in terms of size, fractional bandwidth, peak gain, and radiation efficiency. Therefore, the proposed VBi-UWBA is well suitable for high-speed UWB applications.

\section{Conclusion}

A novel compact bioinspired UWB antenna is investigated in this work. A conventional monopole antenna design formula is adapted to determine the LEF of the proposed bioinspired antenna in this work. The analysis result and computation result agree. The measurement agrees with the simulation result. The proposed VBi-UWBA has a fractional bandwidth of $115.43 \%$ at a $10 \mathrm{~dB}$ return loss, a suitable gain across the wideband, a high radiation efficiency, and a stable omnidirectional radiation pattern which make it a suitable candidate for UWB wireless applications such as sensing, imaging, ground-penetration radar, and personal area network (PAN).

\section{Data Availability}

The data used to support the findings of this study are included within the article.

\section{Conflicts of Interest}

The authors declare that they have no conflicts of interest.

\section{Acknowledgments}

This work was sponsored and supported by the African Union through the Pan African University Institute of Basic Sciences, Technology, and Innovation.

\section{References}

[1] O. E. Maleky and F. B. Abdelouahab, "A UWB antenna with reconfigurable rejection band using split ring resonator for radio cognitive technology," Procedia Manufacturing, vol. 32, pp. 694-701, 2019.

[2] M. Ko and J. Choi, "UWB bow-tie antenna with WLAN/ WiMAX band Application," in Proceedings of the 2018 International Symposium On Antennas And Propagation (ISAP), pp. 1-2, Busan, South Korea, October 2018.

[3] S. M. Hosseini Varkiani and M. Afsahi, "Compact and ultrawideband CPW-fed square slot antenna for wearable applications," AEU-International Journal of Electronics and Communications, vol. 106, no. -115, pp. 108-115, 2019.

[4] G. V. R. Xavier, A. J. R. Serres, E. G. Da Costa, A. C. De Oliveira, L. A. M. M. Nobrega, and V. C. De Souza, "Design and application of a metamaterial superstrate on a bio-inspired antenna for partial discharge detection through dielectric windows," Sensors, vol. 19, no. 19, pp. 4255-19, 2019.

[5] O. M. H. Ahmed and A. R. Sebak, "A novel maple-leaf shaped uwb antenna with a 5.0-6.0 ghz band-notch characteristic," Progress In Electromagnetics Research C, vol. 11, pp. 39-49, 2009.

[6] P. F. Silva Júnior, P. H. d. F. Silva, A. J. R. Serres, J. C. Silva, and R. C. S. Freire, "Bio-inspired design of directional leaf-shaped printed monopole antennas for $4 \mathrm{G} 700 \mathrm{MHz}$ band," Microwave and Optical Technology Letters, vol. 58, no. 7, pp. 1529-1533, 2016.

[7] J. D. N. Cruz, R. C. S. Freire, A. J. R. Serres, L. C. M. D. Moura, A. P. D. Costa, and P. H. D. F. Silva, "Parametric study of printed monopole antenna bioinspired on the inga marginata leaves for UWB applications," Journal of Microwaves, Optoelectronics and Electromagnetic Applications, vol. 16, no. 1, pp. 312-322, 2017.

[8] J. O. Abolade, D. B. O. Konditi, and V. M. Dharmadhikary, "Bio-inspired wideband antenna for wireless applications 
based on perturbation technique," Heliyon, vol. 6, no. 7, Article ID e04282, 2020.

[9] L. Sun, M. He, J. Hu, Y. Zhu, and H. Chen, "A butterflyshaped wideband microstrip patch antenna for wireless communication," International Journal of Antennas and Propagation, vol. 20158 pages, 2015.

[10] K. Ebnabbasi, "A bio-inspired printed-antenna transmissionrange detection system [education column]," IEEE Antennas and Propagation Magazine, vol. 55, no. 3, pp. 193-200, 2013.

[11] P. F. Da-Silva-Júnior, "Bio-inspired wearable antennas," in Wearable Technologies, Janeza Trdine 9, 51000, pp. 219-237, Intech, Rijeka, Croatia, 2018.

[12] K. P. Ray, "Design aspects of printed monopole antennas for ultra-wide band Applications," International Journal of Antennas and Propagation, vol. 2008, p. 8, 2008.

[13] E. Kaivanto, E. Salonen, and H. Khaleel, "Circularly polarized wearable antennas," Innovation in Wearable and Flexible Antennas, vol. 82, pp. 145-161, 2014.

[14] O. Haraz and A.-R. Sebak, "UWB antennas for wireless applications," in Advancement in Microstrip Antennas with Recent Applications Janeza Trdine 9, 51000, K. Ahmed, Ed., pp. 125-152, intechopen, Rijeka, Croatia, 2013.

[15] A. J. R. Serres, "Bio-inspired microstrip antenna," in Trends in Research on Microstrip Antennas, Janeza Trdine 9, 51000, pp. 87-109, Intech, Rijeka, Croatia, 2017.

[16] A. Iqbal, A. Smida, N. Mallat, M. Islam, and S. Kim, "A compact UWB antenna with independently controllable notch bands," Sensors, vol. 19, no. 6, pp. 1411-1412, 2019.

[17] R. A. Santos and S. Arismar Cerqueira, "A low-profile and ultra-wideband printed antenna with a $176 \%$ bandwidth," Journal of Microwaves, Optoelectronics and Electromagnetic Applications, vol. 16, no. 1, pp. 59-69, 2017.

[18] R. Kumar and G. Surushe, "Design of microstrip-fed printed UWB diversity antenna with tee crossed shaped structure," Engineering Science and Technology, an International Journal, vol. 19, no. 2, pp. 946-955, 2016.

[19] R. V. S. R. Krishna and R. Kumar, "A slotted UWB monopole antenna with single port and double ports for dual polarization," Engineering Science and Technology, an International Journal, vol. 19, no. 1, pp. 470-484, 2016.

[20] M. Z. Mahmud, T. Alam, and M. T. Islam, "A triangular coupled-resonator antenna for ultra-wideband applications," Applied Physics A, vol. 123, no. 1, pp. 2-5, 2017.

[21] S. Kundu, "High gain compact ultra-wideband " antennafrequency selective surface" and its performance evaluation in proximity of soil surface," Microwave and Optical Technology Letters, vol. 63, no. 3, pp. 869-875, 2021.

[22] M. Islam, F. Ashraf, T. Alam, N. Misran, and K. Mat, "A compact ultrawideband antenna based on hexagonal splitring resonator for $\mathrm{pH}$ sensor application," Sensors, vol. 18, no. 9, p. 2959, 2018.

[23] A. J. A. Al-Gburi, I. Ibrahim, M. Y. Zeain, and Z. Zakaria, "Compact size and high gain of CPW-fed UWB strawberry artistic shaped printed monopole antennas using FSS single layer reflector," IEEE Access, vol. 8, p. 1, 2020.

[24] L. Xi, H. Zhai, Y. Zang, and L. Li, "A novel dual-band tunable band-notched antenna," Microwave and Optical Technology Letters, vol. 59, no. 12, pp. 3014-3018, 2017.

[25] O. Haraz and A.-R. Sebak, "UWB antennas for wireless applications," in Advancement In Microstrip Antennas With Recent ApplicationsInTech, Rijeka, Croatia, 2013. 